\title{
Improving Battery Design with Electro-Thermal Modeling
}

\author{
Ahmad Pesaran \\ National Renewable Energy Laboratory \\ Golden, Colorado, USA
}




\title{
Acknowledgments
}

\author{
Co-Authors \\ Andreas Vlahinos (AES) \\ Desikan Bharathan (NREL) \\ Gi-Heon Kim (NREL) \\ Tien Duong (DOE)
}

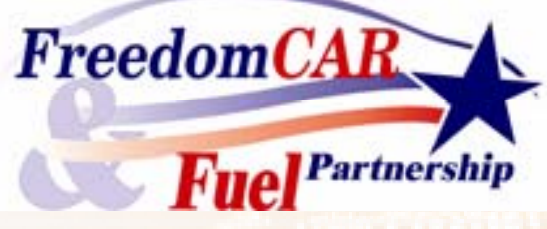

Sponsored by

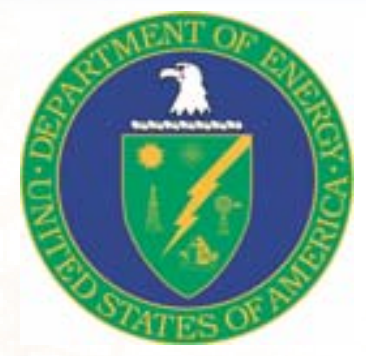

DOE Office of FreedomCAR and Vehicle Technologies

Dave Howell (DOE)

Technical Assistance

Matt Keyser (NREL)

Mark Mihalic (NREL) 


\section{Outline}

- Objectives

- Motivation

- Analysis Approach

- Examples of Analysis/Results

- Comparison with Experimental Data

- Summary \& Conclusions 


\section{Objectives}

\section{General}

- Develop an electro-thermal process/model for predicting thermal performance of real battery cells and modules

- Use the electro-thermal model to evaluate various designs to improve battery thermal performance.

This Study

- Predict the thermal performance of a baseline design and compare it to the performance of a next-generation design

- Baseline: 2001 Panasonic NiMH module

- Next generation: 2004 Panasonic NiMH module

- Verify model results with experiments (infrared thermal imaging) 


\section{Motivation for the Work}

2 - 5 April 2005

- Temperature greatly affects the performance and life (and thus warranty costs) of batteries.

- Battery thermal control/management is a must for hybrid electric vehicles under real driving conditions.

- Good battery pack thermal management starts with cells and modules that perform well thermally.

- Thermal modeling and simulation could aid in designing batteries with better thermal behavior.

- A 3-D model capturing electrical as well as thermal behavior of batteries with real geometries and details including the non-electrochemical parts was needed. 


\section{Analysis Approach}

\section{2 - 5 April 2005}

- Capturing details of a cell including non-electrochemical hardware with Finite Element Analysis.

- Estimating component resistances using geometry and materials.

- Applying voltage drop to calculate current density in components.

- Estimating resistive heating $\left(I^{2} R\right)$ in each component.

- Applying electrochemical heat of reactions in the core (active parts)

- Appling heat transfer boundary conditions on cell exterior.

- Predicting temperature distribution in the cell from current density and related heat generation distribution.
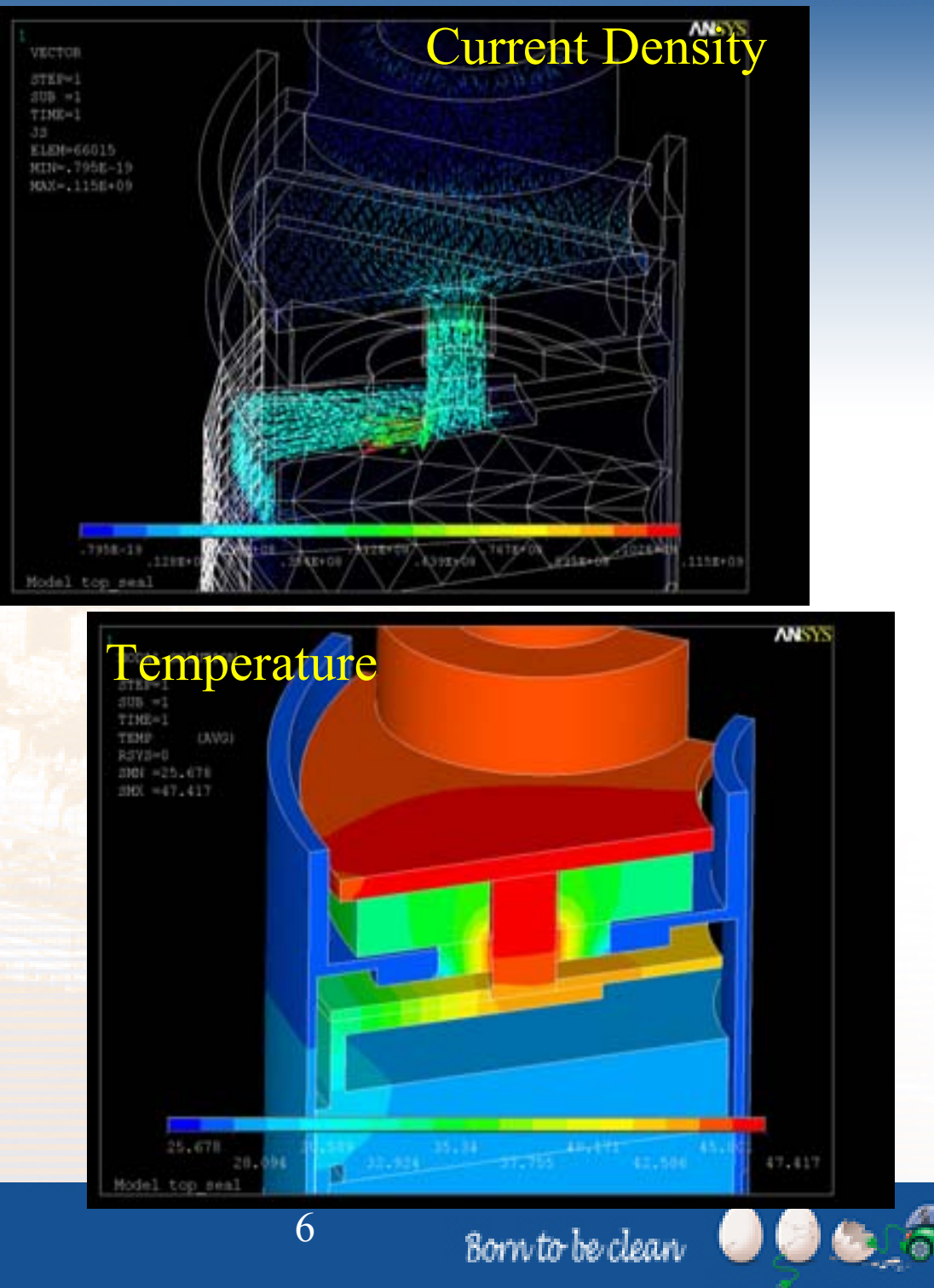
Baseline: 2001 Panasonic Prismatic NiMH module in Toyota Prius

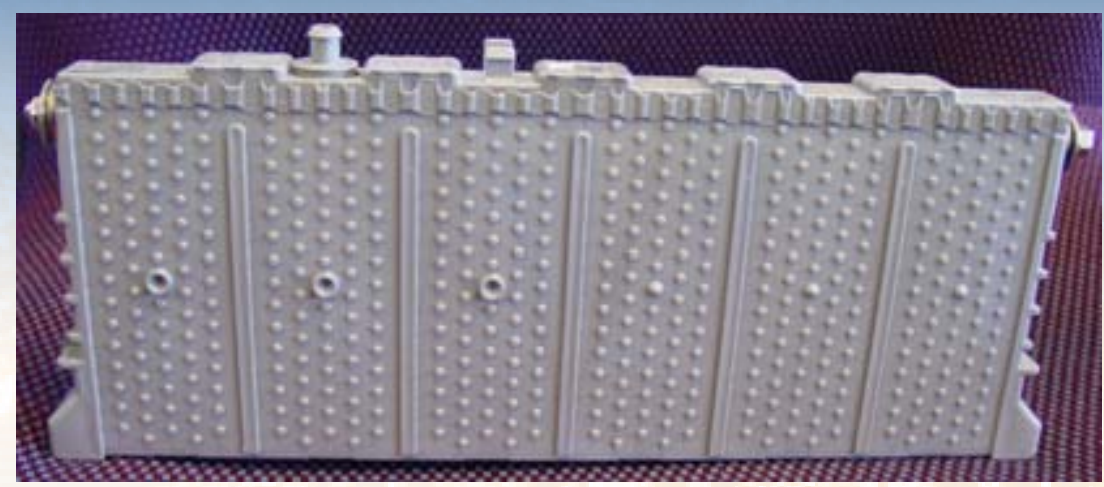

6 cells, $7.2 \mathrm{~V}, 6.5 \mathrm{Ah}, 1000 \mathrm{~W} / \mathrm{kg}$ module $^{\dagger}$

Used Computer Aided Design (CAD) software such as Pro-E or Finite Element Analysis (FEA) tools such as ANSYS for capturing details.

$\uparrow$ Kojiro Ito, EVS-20 proceedings

CAD/FEA model of module (case removed)
CAD/FEA model of module (exterior)

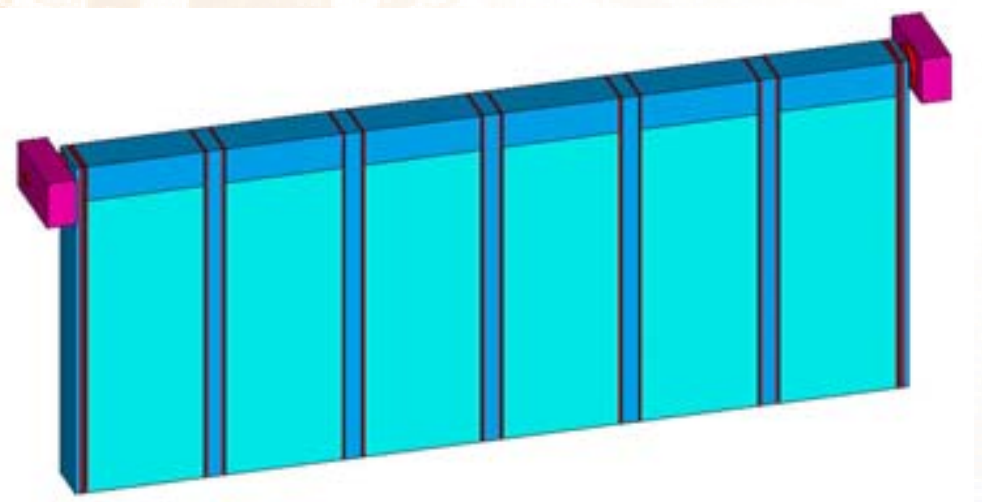


2001 Panasonic Prismatic NiMH Module

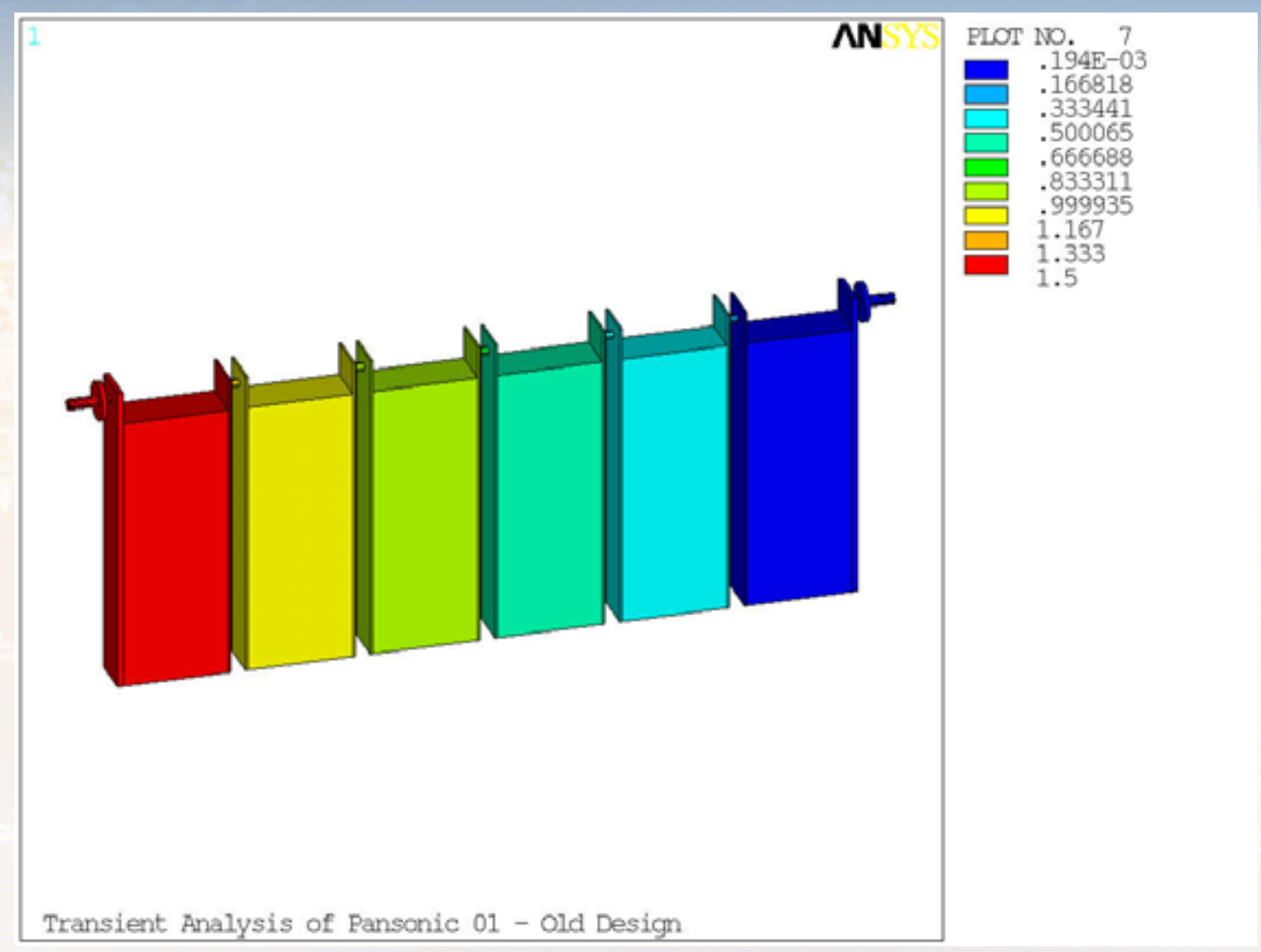


The 21" Worldwide Battery, Hybrid and Fuel Cell Electric Vehiele Symposium \& Exhibition \\ Current Density}

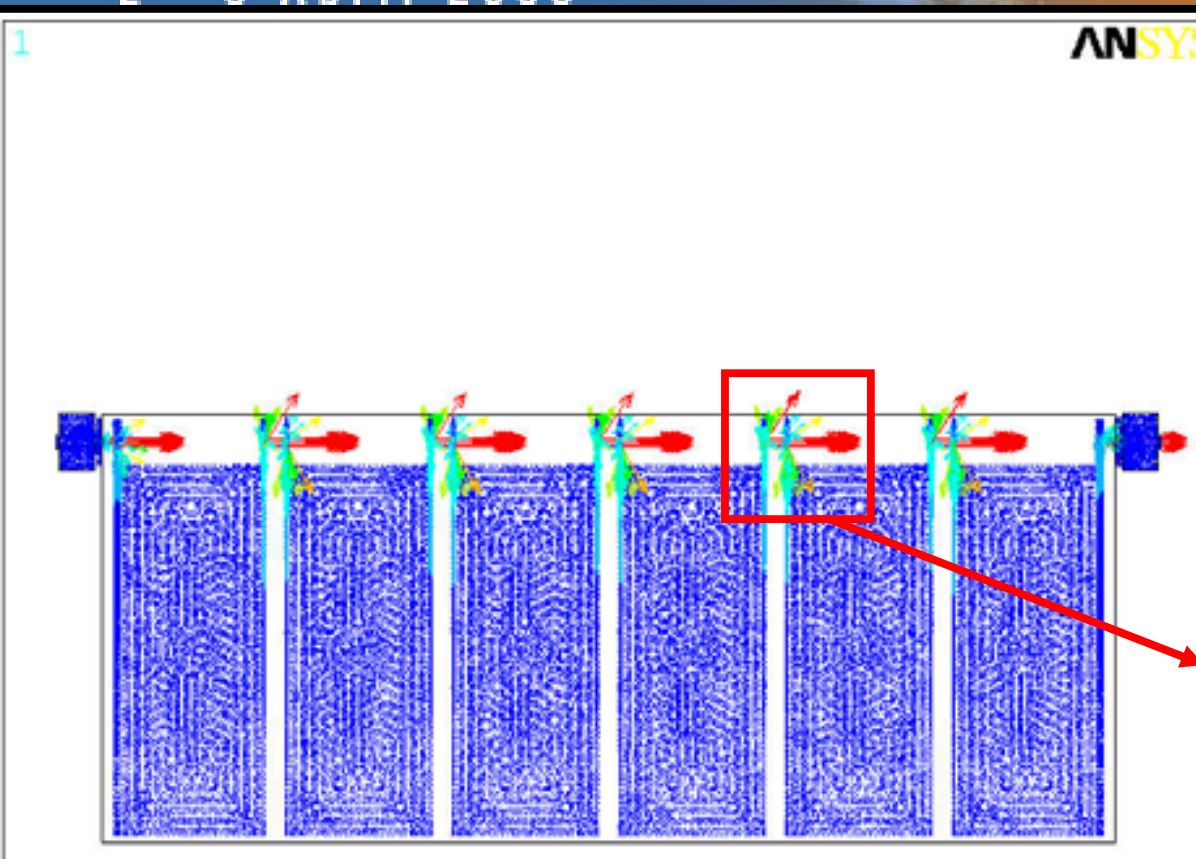

PLOT NO.
0
0
$.300 \mathrm{E}+07$
$.600 \mathrm{E}+07$

$.900 \mathrm{E}+07$

$.120 \mathrm{E}+08$

$.150 \mathrm{E}+08$

$.180 \mathrm{E}+08$

$210 \mathrm{E}+08$

$.240 \mathrm{E}+08$

$.270 \mathrm{E}+08$

100 A constant current discharge

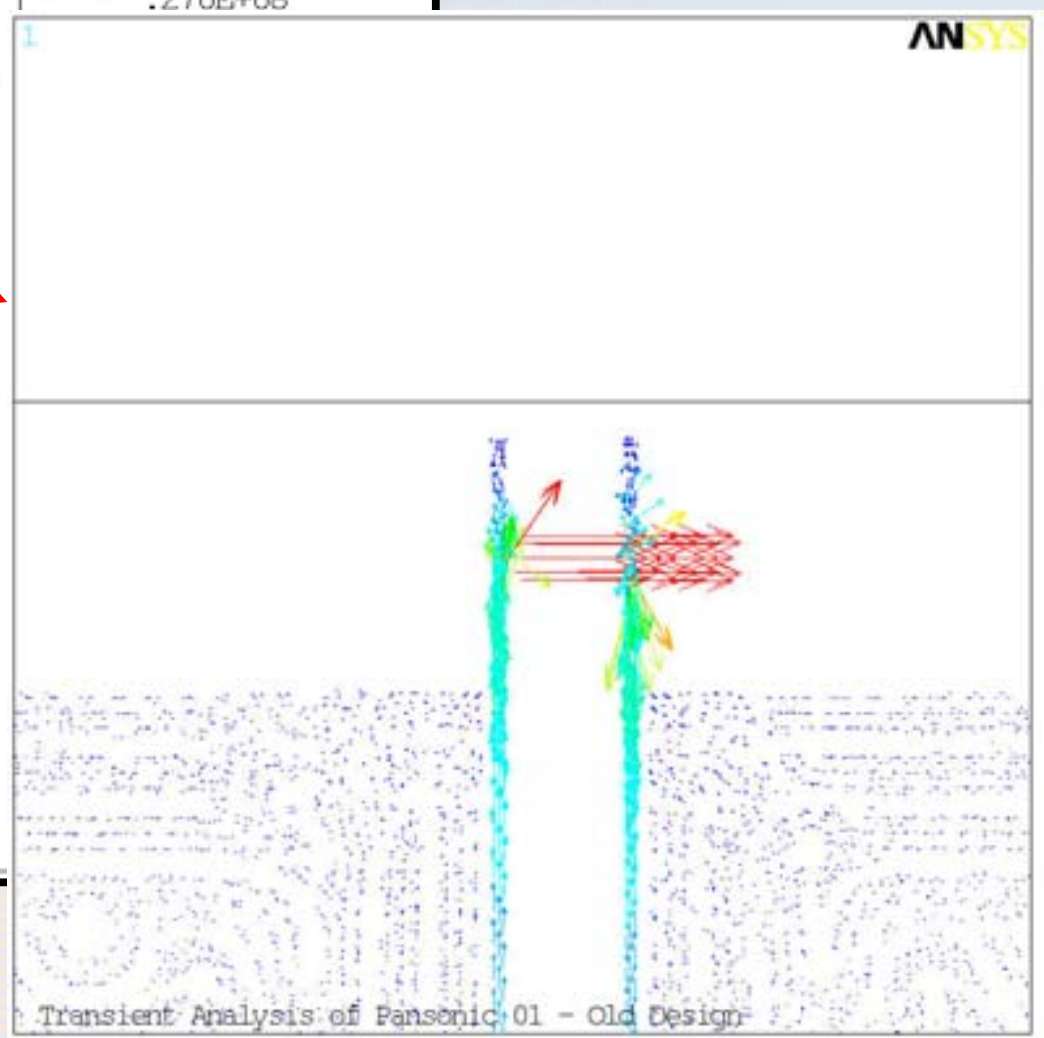




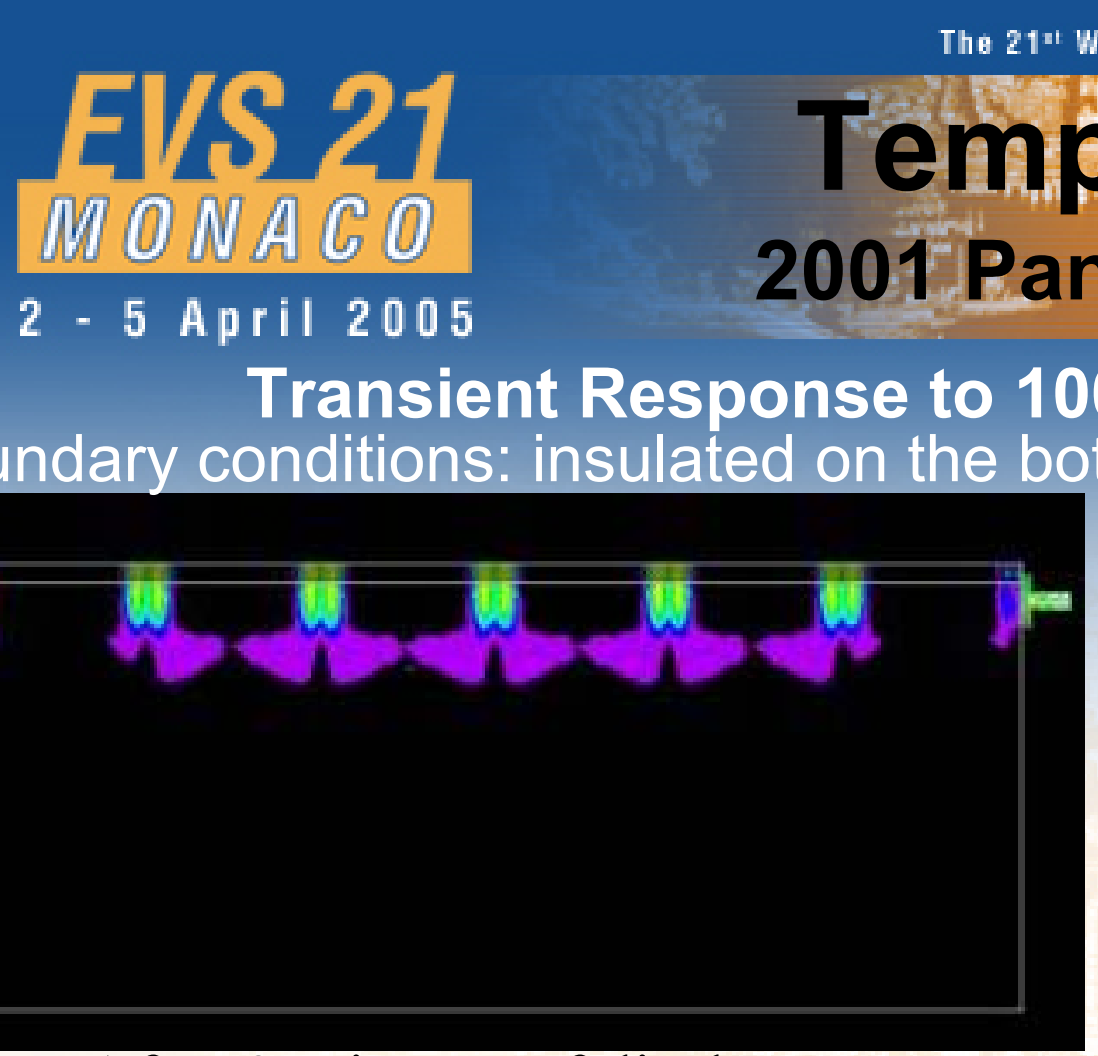

After 2 minutes of discharge

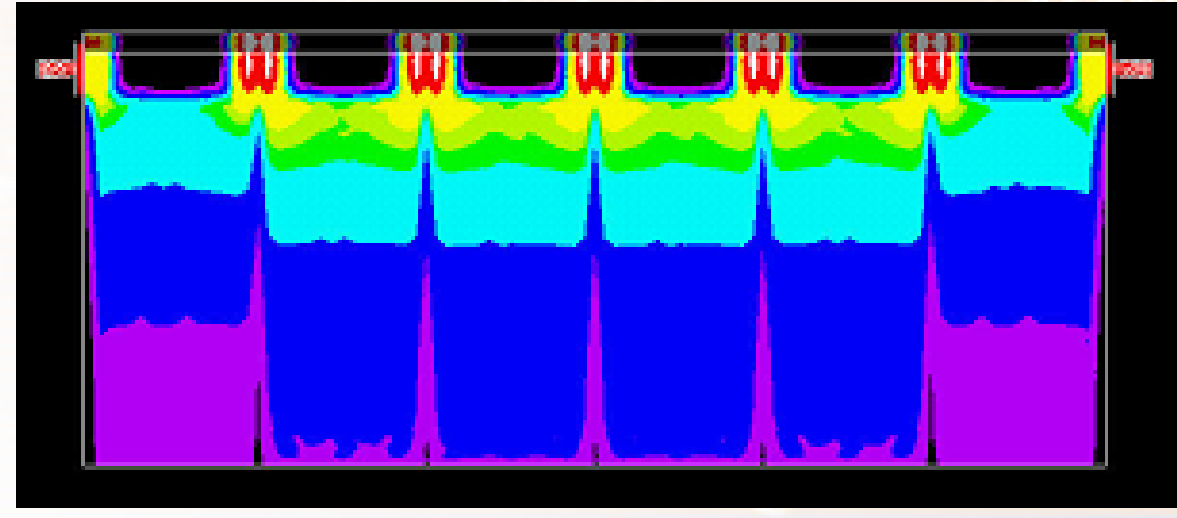

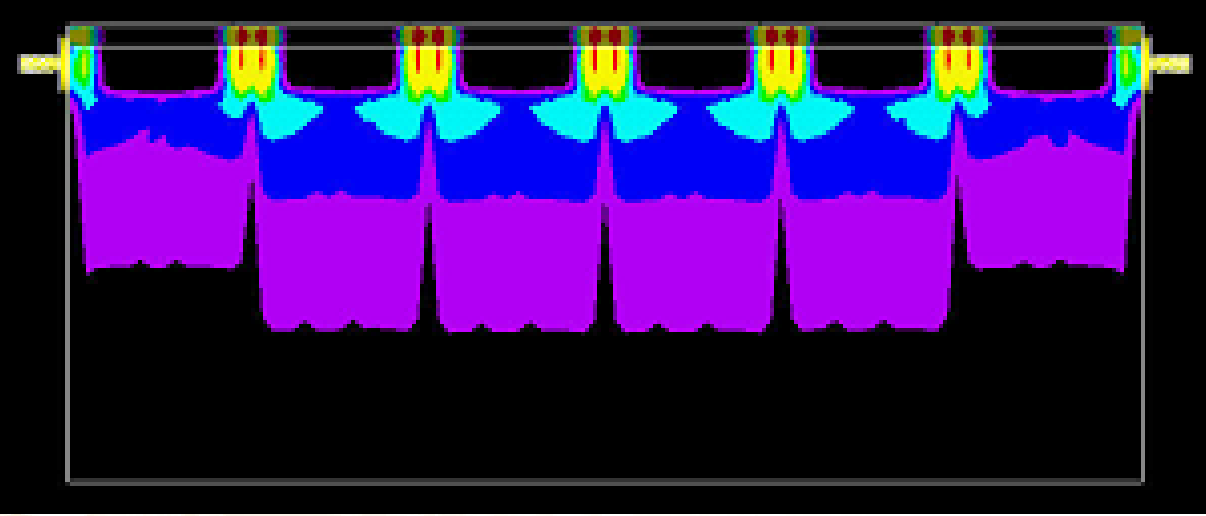

After 2.5 minutes of discharge

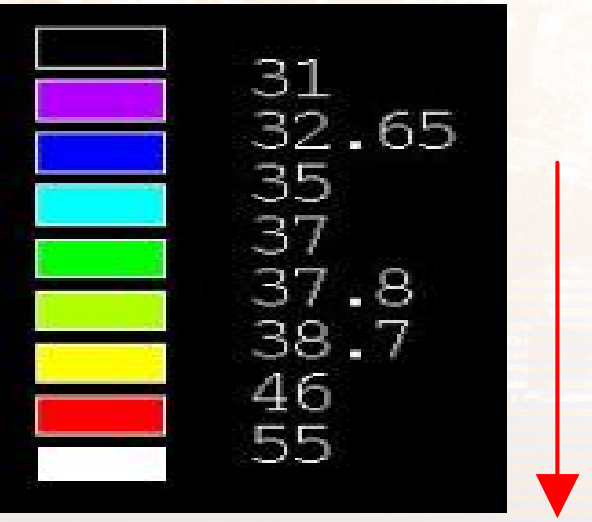

Color scale $\left({ }^{\circ} \mathrm{C}\right)$

Increasing

After 3 minutes of discharge Heat Transfer Coefficient on five sides: $5 \mathrm{~W} /{ }^{\circ} \mathrm{C} / \mathrm{m}^{2}$ Sי 

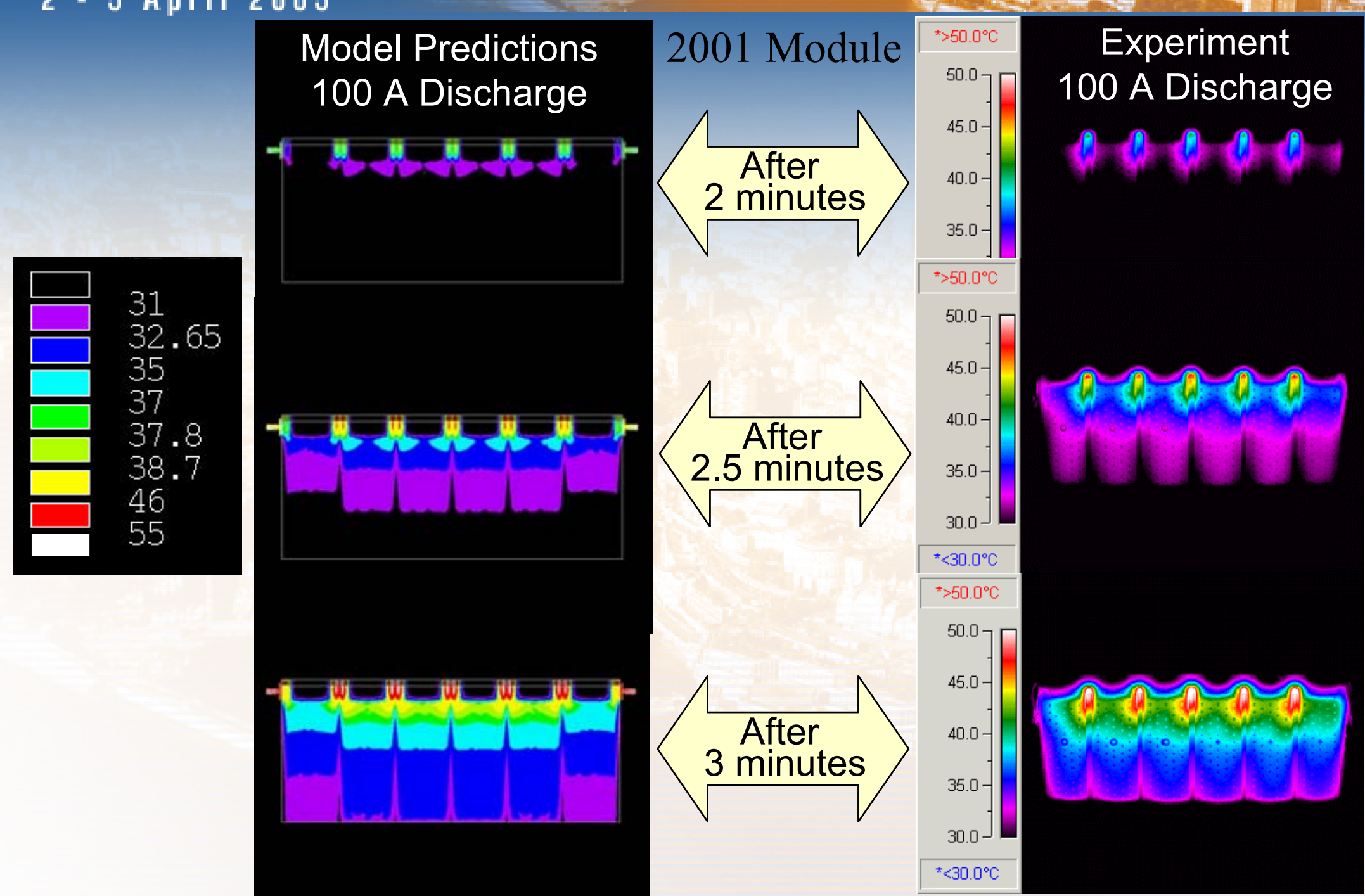
6 cells, 7.2V, 6.5Ah, $1300 \mathrm{~W} / \mathrm{kg}$ module $46 \mathrm{Wh} / \mathrm{kg}, 11.4 \mathrm{mOhm}$ total DC resistance
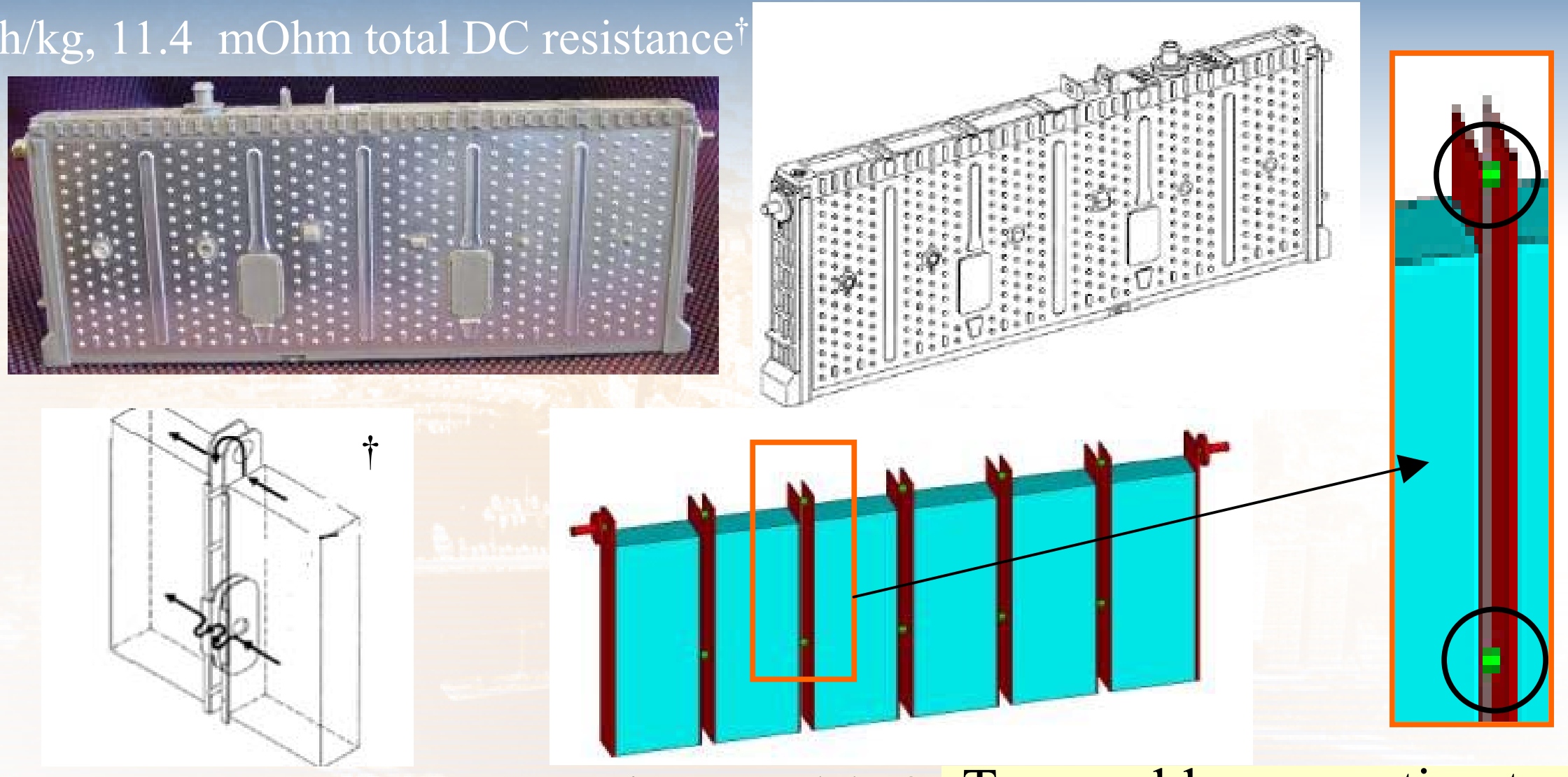

CAD/FEA model of $\dagger$ Kojiro Ito, EVS-20 proceedings connectors \& cells

Two welds connecting two cells in series ${ }^{\dagger}$ 
The 21" Worldwide Battery, Hybrid and Fuel Cell Electric Vehicle Symposium \& Exhibition

EI/S 21 MONACO

2 - 5 April 2005

\section{for 100 A discharge of 2004 Module}

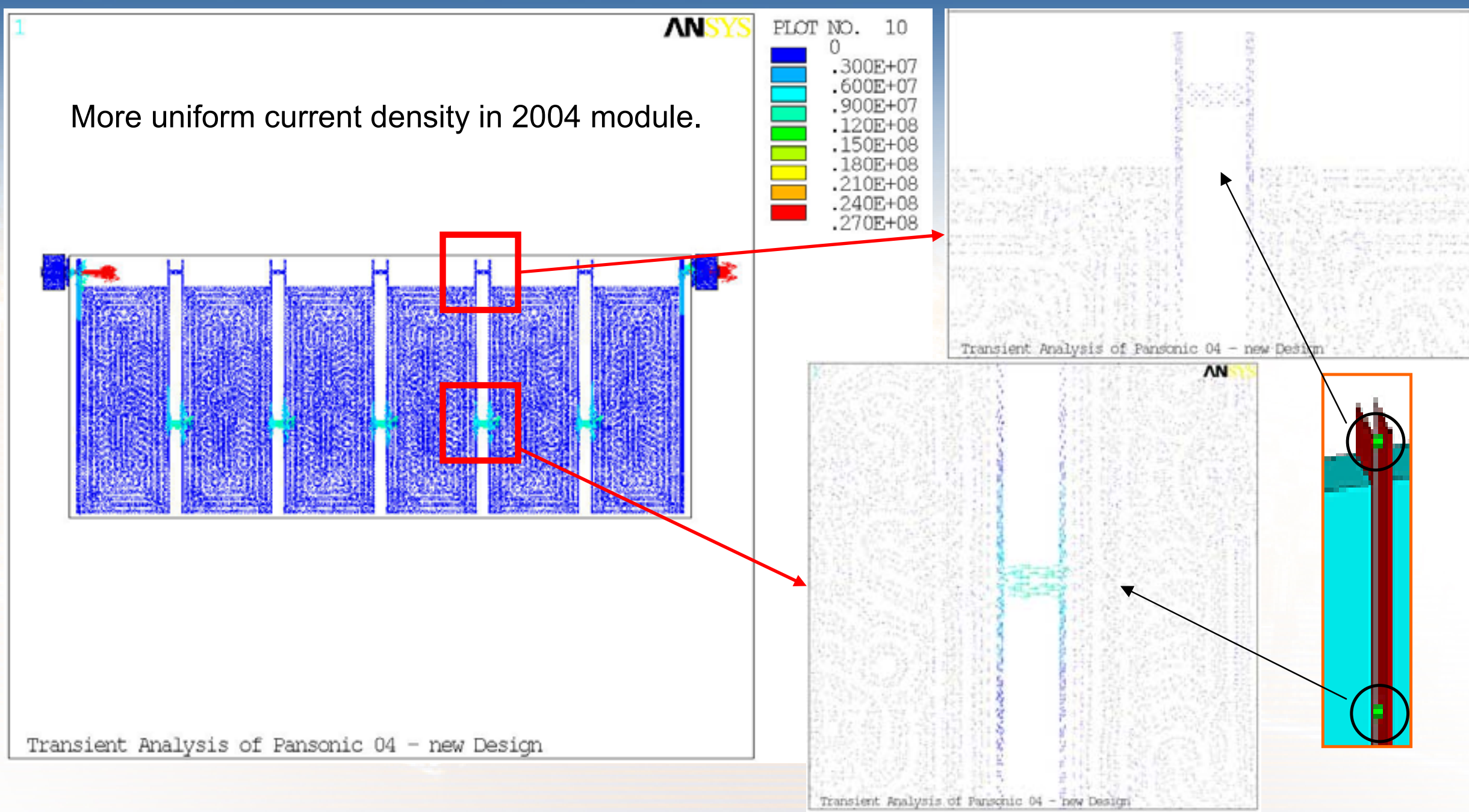

\section{in}

$\underset{\text { FreedomCAR }}{\stackrel{\text { Partmonap }}{\longrightarrow}}$ 


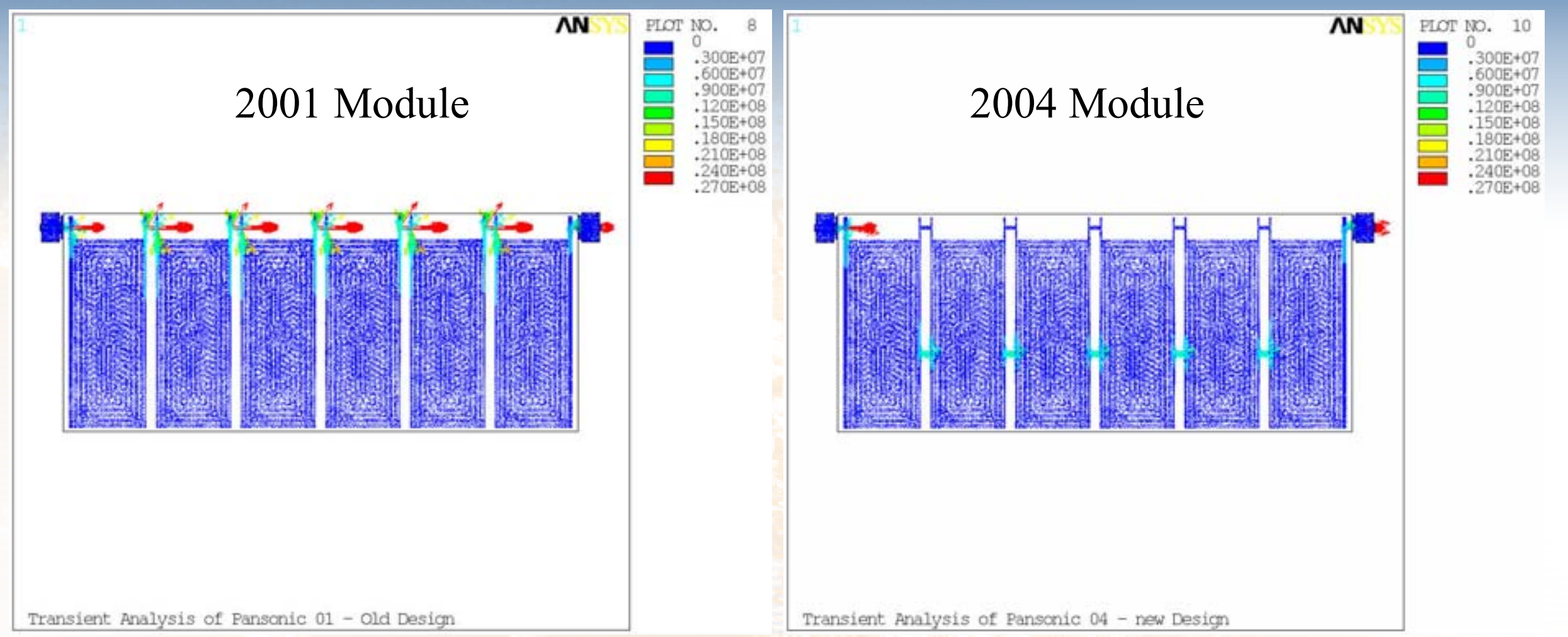

The model predicted lower and more uniform current density in 2004 module. 


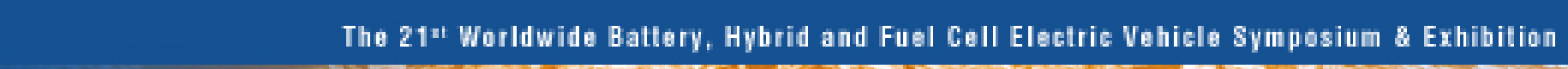

EISS 21

MO ONAGO

2 - 5 April 2005 Comparing Temperature

\section{Distributions (model \& test)}

Response at the end of to 100A Constant Current Discharge ( $3 \mathrm{~min}$ )

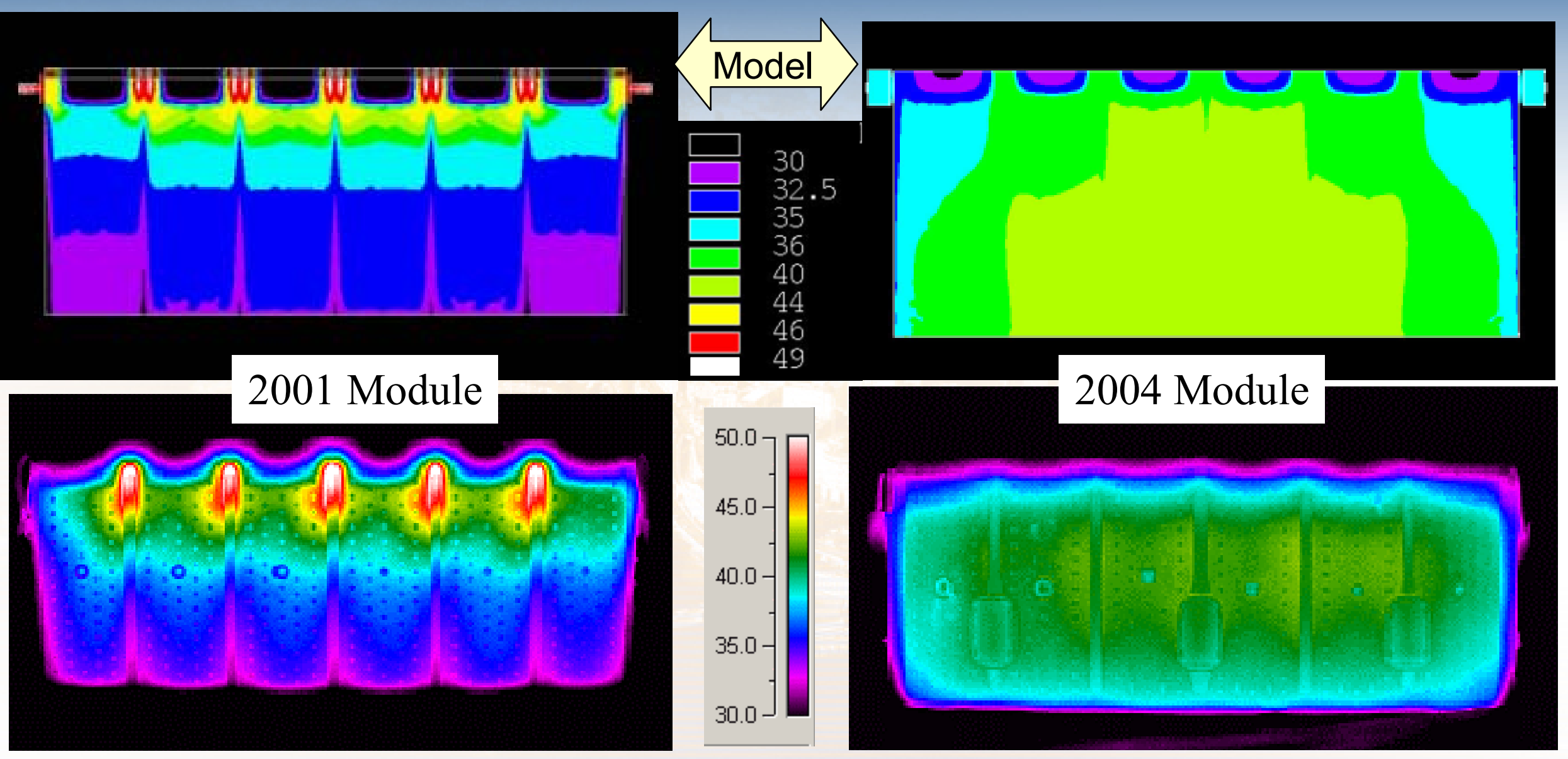

The model predicted lower and more uniform temperature distribution in 2004 module.

(i) FreedomCAR

19

Bomtobe dean

000.6 


\section{Summary and Conclusions}

2 - 5 April 2005

- We developed the process of electro-thermal modeling for battery cells and modules with real geometries.

- The model is used to predict the current and temperature distributions in batteries for improving designs.

- We applied the modeling approach to two generation designs of prismatic Panasonic NiMH modules.

- The model results were in good agreement of thermal imaging of real modules under $100 \mathrm{~A}$ constant current discharge.

- The model predicted that adding a second set of welds to interconnects could reduced the overall temperature and improve temperature uniformity. (This is what Panasonic did in their 2004 module.)

- The electro-thermal model could be applied to other chemistries (lithium ion) and any geometry (cylindrical). 